\title{
Rheological Properties of Very High-Strength Portland Cement Pastes: Influence of Very Effective Superplasticizers
}

\author{
Adriano Papo, Luciano Piani, and Riccardo Ricceri \\ Dipartimento di Scienze e Tecnologie Chimiche, Università degli Studi di Udine, Via Cotonificio 108, 33100 Udine, Italy \\ Correspondence should be addressed to Luciano Piani, luciano.piani@uniud.it
}

Received 1 October 2009; Accepted 25 January 2010

Academic Editor: Dilhan M. Kalyon

Copyright (c) 2010 Adriano Papo et al. This is an open access article distributed under the Creative Commons Attribution License, which permits unrestricted use, distribution, and reproduction in any medium, provided the original work is properly cited.

The influence of the addition of very effective superplasticizers, that are commercially available, employed for maximising the solid loading of very high-strength Portland cement pastes, has been investigated. Cement pastes were prepared from deionized water and a commercially manufactured Portland cement (Ultracem 52.5 R). Cement and water were mixed with a vane stirrer according to ASTM Standard C305. The 0.38 to 0.44 water/cement ratio range was investigated. Three commercial superplasticizing agents produced by Ruredil S.p.a. were used. They are based on a melamine resin (Fluiment $33 \mathrm{M}$ ), on a modified lignosulphonate (Concretan $200 \mathrm{~L}$ ), and on a modified polyacrylate (Ergomix 1000). Rheological tests were performed at $25^{\circ} \mathrm{C}$ by using the rate controlled coaxial cylinder viscometer Rotovisko-Haake 20, system M5-osc., measuring device MV2P with serrated surfaces. The tests were carried out under continuous flow conditions. The results of this study were compared with those obtained in a previous article for an ordinary Portland cement paste.

\section{Introduction}

The rheological properties of fresh cement pastes are very interesting, since they strongly affect the consistency, workability, and setting characteristics of the cement.

Knowledge of the rheological properties of fresh cement pastes may contribute to supply a useful tool for controlling cement production, for achieving further information on the chemistry of cement as well as to a better understanding of flow behaviour of mortars and concrete.

Moreover, understanding of how to control the rheological properties of fresh cement pastes is very important for the economical proportioning of concrete and proper mixing and placement methods, in particular for special applications.

Fresh cement pastes are highly concentrated suspensions; their rheological behaviour is generally very complex and is dependent on several factors of different nature, such as:

(i) physical factors (the water/cement ratio, the cement grain shape and size, etc.), (ii) chemical and mineralogical factors (the cement composition and its structural modifications due to hydration processes, etc.),

(iii) mixing conditions (stirrer type and rate, the stirring time, etc.),

(iv) measurement conditions (the measuring instruments and the experimental procedures, etc.),

(v) presence of additives (water reducing agents, superplasticizers, etc.).

A lot of experimental works on cement paste rheology is available in the literature; reference is made here to the most recent papers [1-22].

This work is a part of a research study concerning the influence of the addition of some commercially available superplasticizers that were shown to be very effective on the rheological behaviour of fresh very high-strength Portland cement pastes: in a previous work the effect of superplasticizers of different formulation using the same type of cement has been reported [22]. Superplasticizers are 
nowadays widely employed in cement technology, since they give a better workability at a fixed water/cement ratio, or, on the other hand, they allow to obtain the same workability as that of the plain cement paste but with a great reduction in water content; hence, manufacts can be prepared with lower porosity and, consequently, with higher mechanical strengths and durability [15-20]. From a rheological point of view, the addition of water reducing agents and, in particular, the use of superplasticizers modifies the flow behaviour of pastes in that they can reduce the attractive forces among cement particles, thus promoting particle dispersion. In fact, cement particles are generally negatively charged: the addition of negatively charged dispersants to cement suspensions affects the particle surface charge by reducing its zeta potential thus favouring repulsion among particles until the saturation adsorption limit of dispersing agent is attained. This phenomenon occurs in correspondence to a critical dispersant concentration: as a result, electrostatic stabilization takes place. Moreover, the employment of polymeric deflocculants induces a mechanism of particle stabilization which results from steric interactions combined with electrostatic repulsions [23, 24].

In a previous article [5], the authors have already studied the effect of three superplasticizers on the rheological behaviour of some ordinary Portland cement 32.5 R (OPC) pastes.

The superplasticizers investigated in [5] were based on (1) a melamine resin (Fluiment $33 \mathrm{M}$ ), (2) a modified lignosulphonate (Concretan $200 \mathrm{~L}$ ), and (3) a modified polyacrylate (Ergomix 1000). The present work extends the study of the effect of the addition of these superplasticizers to a very high-strength Portland cement, Ultracem 52.5 R (HSPC). Ultracem $52.5 \mathrm{R}$ is particularly used for prefabrication, for particularly high structures, and for quick-acting cement casting as well [25].

In details, the superplasticizers here employed present the following characteristics [26]: Fluiment $33 \mathrm{M}$ is an accelerating agent. Among superplasticizers, it distinguishes itself by the high dosage of employment that allows to maintain workability for pastes made at low w/c ratio without reduction of mechanical performances, to enhance durability with respect to the action of atmospheric agents, since it brings about the formation of a cement microstructure of less porosity, and finally to obtain more compact manufacts than those produced without additive addition. Concretan RX is a retarding agent; it improves workability and homogeneity of pastes made with low water/cement ratio, thus providing a better reproducibility in developing mechanical strength and enhancing durability with respect to the action of atmospheric agents of final manufact. Ergomix 1000 is an accelerating agent. Its mechanism of action is based on electrostatic repulsion combined with hyndrance phenomena exerted by polyacrylic chains upon cement particles, that allows to produce manufacts with very low water/cement ratio and high mechanical strength as well as maintaining a good workability.

The aim of this work is to check the effectiveness of the superplasticizers investigated and to determine their optimum dosage by using rheological techniques and compare
TABLE 1: Chemical composition and physical properties of Ultracem $52.5 \mathrm{R}$.

\begin{tabular}{|c|c|c|c|c|}
\hline \multicolumn{2}{|c|}{ Chemical analysis (\%) } & & \multicolumn{2}{|c|}{ Physical tests } \\
\hline $\begin{array}{l}\text { Calcium oxide } \\
(\mathrm{CaO})\end{array}$ & 63.23 & & $\begin{array}{l}\text { Specific gravity } \\
\left(\mathrm{g} / \mathrm{cm}^{3}\right)\end{array}$ & 3.14 \\
\hline Silica $\left(\mathrm{SiO}_{2}\right)$ & 20.02 & & $\begin{array}{l}\text { Specific surface } \\
\text { Blaine }\left(\mathrm{cm}^{2} / \mathrm{g}\right)\end{array}$ & 4000 \\
\hline $\begin{array}{l}\text { Alumina } \\
\left(\mathrm{Al}_{2} \mathrm{O}_{3}\right)\end{array}$ & 4.12 & & $\begin{array}{l}\text { Compressive } \\
\text { strength (MPa) }\end{array}$ & \\
\hline $\begin{array}{l}\text { Iron oxide } \\
\left(\mathrm{Fe}_{2} \mathrm{O}_{3}\right)\end{array}$ & 1.87 & & 2 days & 33.0 \\
\hline $\begin{array}{l}\text { Sulfur trioxide } \\
\left(\mathrm{SO}_{3}\right)\end{array}$ & 3.43 & & 28 days & 55.0 \\
\hline $\begin{array}{l}\text { Magnesia } \\
(\mathrm{MgO})\end{array}$ & 4.2 & & $\begin{array}{l}\text { Setting time, } \\
\text { Vicat test (min) }\end{array}$ & \\
\hline $\begin{array}{l}\text { Sodium oxide } \\
\left(\mathrm{Na}_{2} \mathrm{O}\right)\end{array}$ & 0.003 & & Initial setting & 160 \\
\hline $\begin{array}{l}\text { Potassium oxide } \\
\left(\mathrm{K}_{2} \mathrm{O}\right)\end{array}$ & 0.0015 & & Final setting & 200 \\
\hline Loss on ignition & 0.80 & & $\begin{array}{l}\text { BET specific } \\
\text { surface area } \\
\left(\mathrm{m}^{2} / \mathrm{g}\right)\end{array}$ & 1.82 \\
\hline $\begin{array}{l}\text { Phase } \\
\text { composition }\end{array}$ & $\begin{array}{c}\mathrm{C}_{3} \mathrm{~S} \\
49.1 \% \\
\end{array}$ & $\begin{array}{c}\mathrm{C}_{2} \mathrm{~S} \\
19.7 \% \\
\end{array}$ & $\begin{array}{l}\mathrm{C}_{3} \mathrm{~A} \\
7.91 \%\end{array}$ & $\begin{array}{l}\mathrm{C}_{4} \mathrm{AF} \\
5.2 \% \\
\end{array}$ \\
\hline
\end{tabular}

the rheological characteristics of HSPC pastes with those presented by OPC pastes already studied.

\section{Experimental Part}

2.1. Materials. Cement pastes were prepared from deionized water and a commercially manufactured Portland cement Ultracem 52.5 R (Italcementi S.p.a., Bergamo, Italy) containing 95\% of clinker, according to UNI EN 197/1. Cement chemical composition and physical properties are reported in Table 1. Cement pastes were prepared with a vane stirrer (Ultra-Turrax T50, Janke \& Kunkel, IKA-Labortechnik, Germany) according to ASTM Standard C305. Plain HSPC pastes were prepared in the range 0.38 to 0.44 water/cement ratio $(\mathrm{W} / \mathrm{C}), 0.38$ being the lowest $\mathrm{W} / \mathrm{C}$ ratio of the sample that can be loaded into the viscosimetric cup (the highest measurable viscosity of our rheometer has been taken as reference).

Three commercial superplasticizing agents produced by Ruredil S.p.a., S. Donato Milanese (Mi), Italy, were used. They are based on the following:

(1) a melamine resin (Fluiment $33 \mathrm{M}$; recommended dosage: $1-5 \mathrm{~mL} / 100 \mathrm{~g}$ of cement),

(2) a modified lignosulphonate (Concretan $200 \mathrm{~L}$; recommended dosage: $0.7-1.5 \mathrm{~mL} / 100 \mathrm{~g}$ of cement),

(3) a modified polyacrylic resin (Ergomix 1000; recommended dosage: $0.5-1.5 \mathrm{~mL} / 100 \mathrm{~g}$ of cement).

The superplasticizers were employed within a concentration range including the dosage recommended by the producer. 
2.2. Apparatus and Procedures. Rheological measurements were carried out by using the rate controlled coaxial cylinder viscometer Rotovisko-Haake 20, system M5-Osc., measuring device MV2P with serrated surfaces. The temperature was kept strictly constant at $25 \pm 0.1^{\circ} \mathrm{C}$. The tests were accomplished under continuous flow conditions by applying the following rheological procedure: a first hysteresis cycle was drawn immediately after mixing; changes in shear rate were made at the constant shear acceleration of $7.31 \mathrm{~s}^{-2}$; maximum shear rate $=439 \mathrm{~s}^{-1}$. The same sample was then subjected to a second hysteresis cycle 1 minute after the previous one. The down curves of the second hysteresis loop have been utilized as flow curves for the cement pastes examined.

The mixing conditions were kept constant for all experiments reported in this article. Preliminary tests have shown that differences in measurements due to uncompleted dispersion of the samples were not found in any case for all experiments. Moreover, preliminary tests have also shown that the chosen ramp rate allows for viscosity measurements to be performed in steady-state conditions, so that no mistakes due to wrong interpretation of rheological behaviour of the samples could be made.

Rheological measurements were reported plotting shear rate versus apparent viscosity, although "apparent shear rate" is probably more appropriate than "shear rate" in this kind of experiments.

BET specific surface area measurements were carried out by using the Tristar surface area analyser by Micromeritics.

The cement powder samples analysed were previously subjected to $150^{\circ} \mathrm{C}$ for 1.5 hours under vacuum.

\section{Results and Discussion}

According to the rheological procedure which has been described above, two hysteresis cycles were drawn after sample preparation. In the case of the cement pastes prepared without additives, the first hysteresis cycle shows a shape similar to that already described in previous paper [6]: the down curve lies on the lower shear stress side with respect to the upper one; that is, structure breaks down during tests; the second hysteresis cycle loop presents both up and down curves of shear-thinning type and the rheological behaviour is in this case strictly thixotropic (see Figure 1). This kind of rheological behaviour is not unlikely for cement pastes (see, e.g., $[3,5,6]$ ), although yield stress cannot be excluded for viscosity measurements performed on plain cement pastes.

Mechanical energy transfer during viscosity measurements (that could be different from that occurring during mixing in sample preparation) could account for structure breakup during hysteresis cycles, but a wall slip mechanism cannot be excluded [27-31].

The addition of superplasticizers reduces hysteresis area of the first hysteresis cycle and brings about some modifications in the pattern of the second histeresis cycle, in that its down curve lies on the lower shear stress side with respect to the upper one for each superplasticizer and for each additive concentration, thus indicating that structure

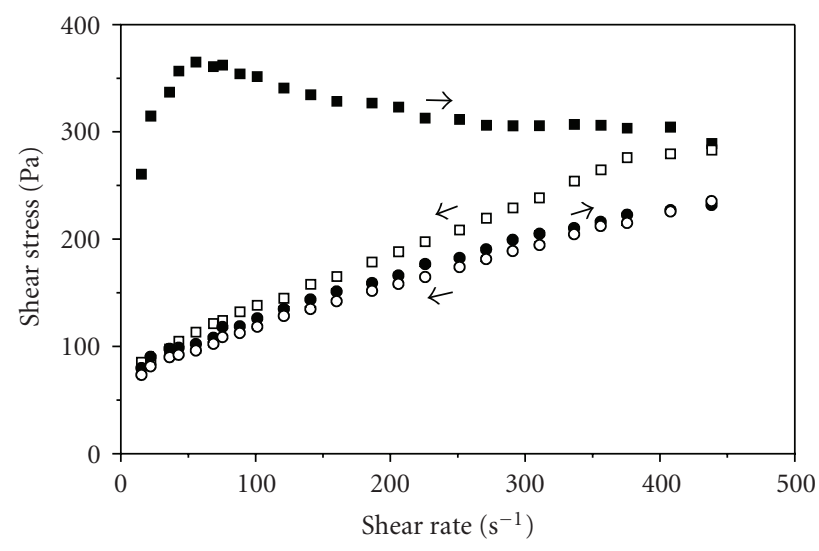

FIGURE 1: Shear stress versus shear rate hysteresis cycle for the W/C $=0.38$ HSPC paste.

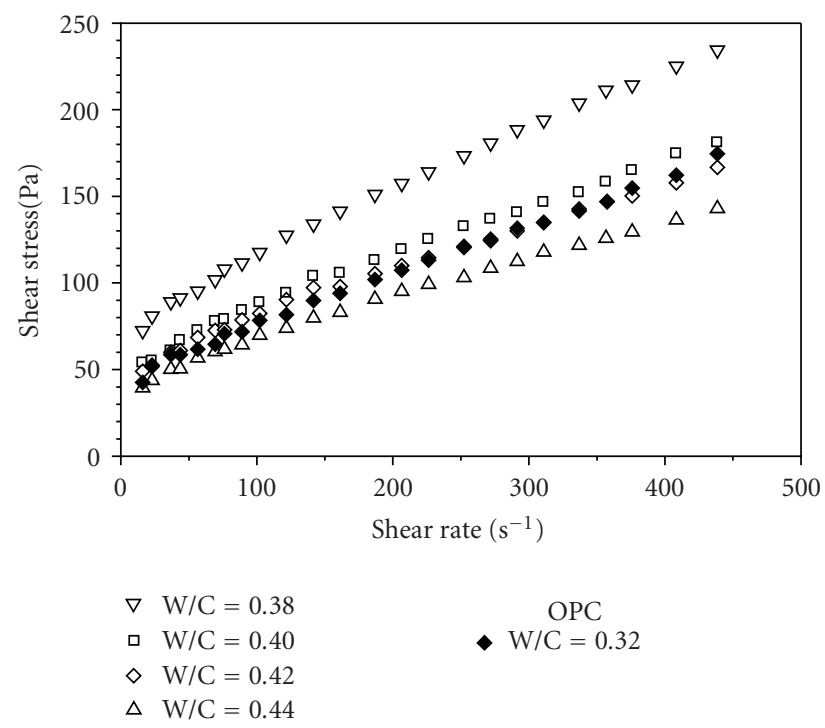

FIGURE 2: Shear stress versus shear rate flow curves for the HSPC pastes investigated and for the $\mathrm{W} / \mathrm{C}=0.32 \mathrm{OPC}$ paste.

breaks down; nevertheless, similarly to that already shown in previous paper [5], the down curve may be of Newtonian, shear-thinning or shear-thickening type, depending on the nature and amount of additive.

Figure 2 reports the shear stress versus shear rate flow curves determined for the HSPC pastes prepared without superplasticizer. The $\mathrm{W} / \mathrm{C}=0.32$ ordinary Portland cement $32.5 \mathrm{R}$ (OPC) paste flow curve is taken as reference (see [5]).

By examining Figure 2 the following can be noticed:

(a) a shear-thinning behaviour is made evident for each w/c ratio by using HSPC pastes;

(b) the shear stress of W/C $=0.38 \mathrm{HSPC}$ paste is far higher than the OPC paste prepared with $\mathrm{W} / \mathrm{C}=0.32$;

(c) the W/C $=0.42 \mathrm{HSPC}$ paste shows practically the same shear stress and consequently the same viscosity of the OPC paste prepared with $\mathrm{W} / \mathrm{C}=0.32$. 


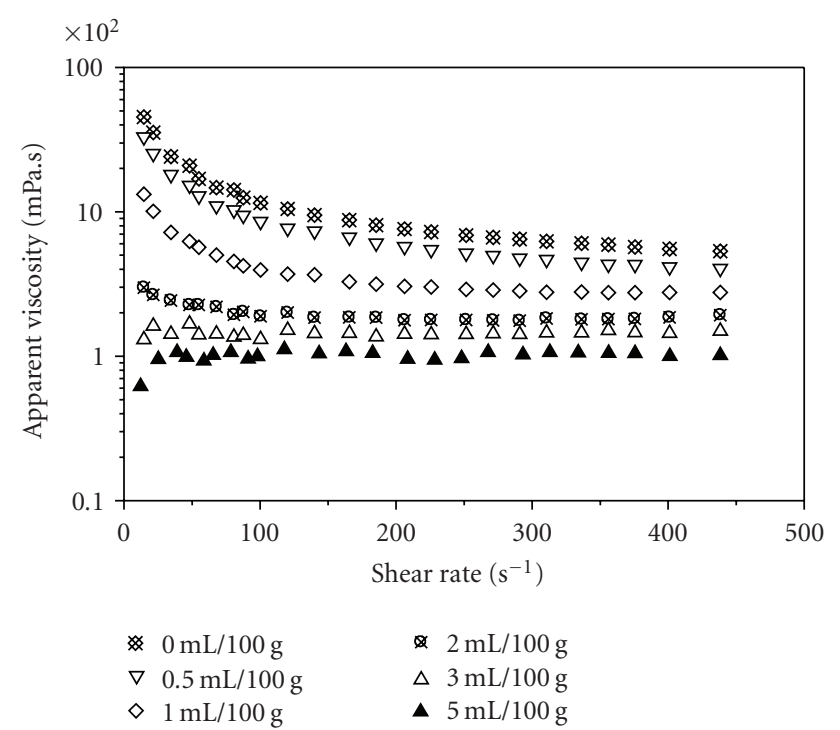

Figure 3: Apparent viscosity versus shear rate flow curves for the $\mathrm{W} / \mathrm{C}=0.38 \mathrm{HSPC}$ pastes investigated at various Fluiment $33 \mathrm{M}$ concentrations.

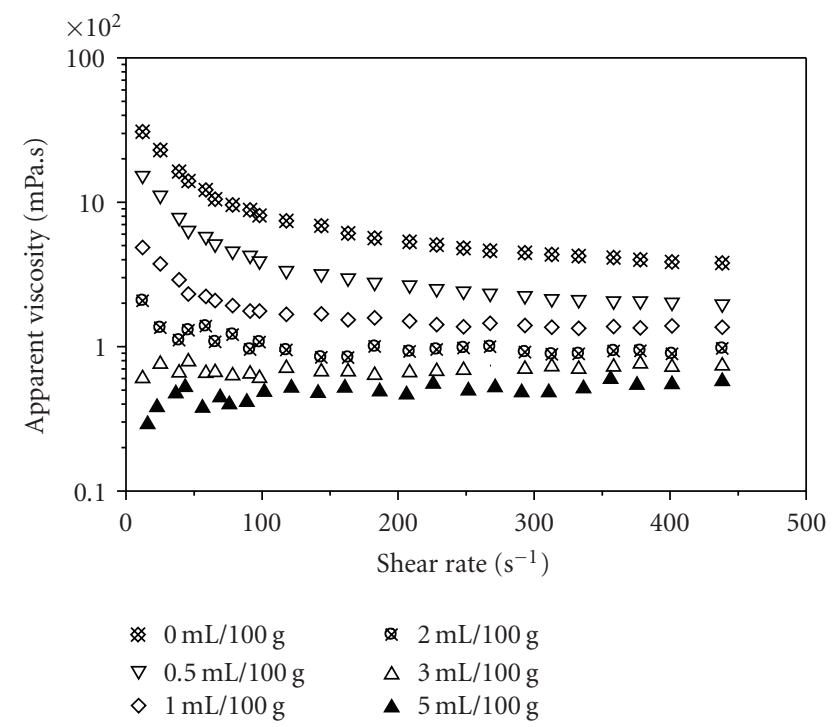

FIGURe 4: Apparent viscosity versus shear rate flow curves for the $\mathrm{W} / \mathrm{C}=0.42 \mathrm{HSPC}$ pastes investigated at various Fluiment $33 \mathrm{M}$ concentrations.

Therefore, it occurs that HSPC plain pastes are far more viscous than OPC pastes formulated with the same water/cement ratio. This is in good accordance with BET surface area of $1.82 \mathrm{~m}^{2} / \mathrm{g}$ found for HSPC powders (Table 1), which is much higher than $1.38 \mathrm{~m}^{2} / \mathrm{g}$ found for ordinary Portland cement $32.5 \mathrm{R}$ (OPC) [5] taken as a reference. The higher surface area corresponds to a higher water adsorption and higher interparticle interactions, resulting in higher viscosity of the paste at the same solid content. Consequently, the effect of superplasticizers addition upon the HSPC pastes has been studied by taking into consideration two

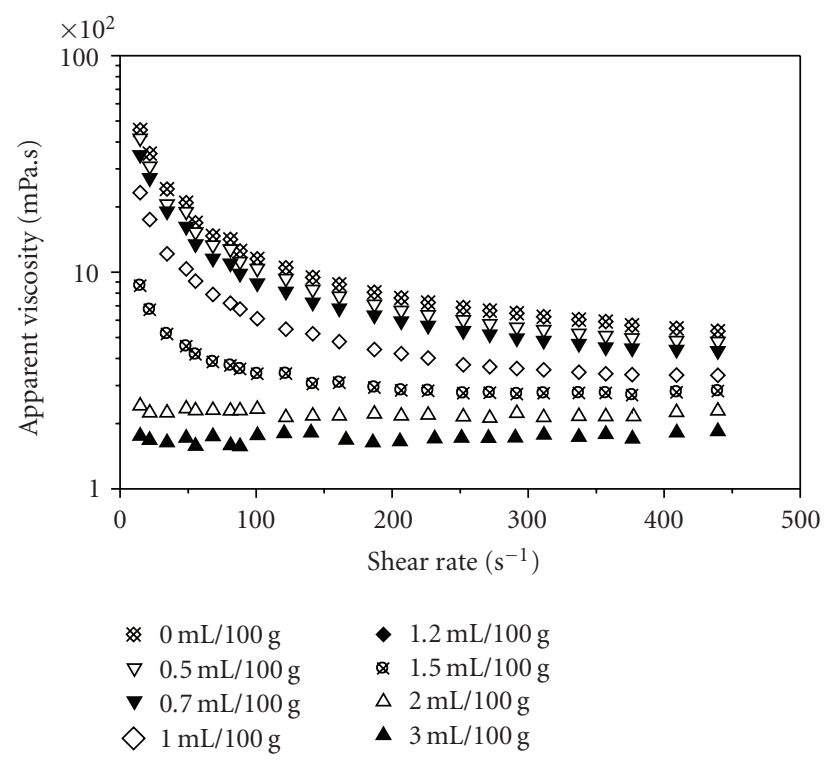

Figure 5: Apparent viscosity versus shear rate flow curves for the $\mathrm{W} / \mathrm{C}=0.38 \mathrm{HSPC}$ pastes investigated at various Concretan $200 \mathrm{~L}$ concentrations.

water/cement ratios $(0.38$ and 0.42$)$; the results are reported in Figures 3, 4, 5, 6, 7, and 8.

From an examination of Figures $3,4,5,6,7$, and 8 it follows that flow curves are strongly dependent on both the nature and the amount of superplasticizer. A yield stress is also made evident for all the pastes investigated within the whole range of dispersant concentration explored. Moreover, it can be observed that all the pastes prepared with the addition of any of the superplasticizers here studied present an initial shear-thinning behaviour up to a limit deflocculant concentration, above which an almost Newtonian behaviour takes place and persists up to high superplasticizer concentration in the presence of Fluiment 33 $\mathrm{M}$ and Concretan $200 \mathrm{~L}$, while a shear-thickening behaviour occurs particularly evident at low shear rate in the case of Ergomix 1000.

Shear-thinning characteristics are typical of agglomerated suspensions such as cement pastes, where, at low shear rates, the attractive interparticle forces are predominant over the hydrodynamic ones, leading to the formation of flocs. When increasing shear rate, the hydrodynamic forces exerted by the flow field become higher and higher; consequently, flocs are broken down into smaller and smaller flow units and the liquid entrapped within them is gradually released; this results in viscosity decrease. The almost Newtonian behaviour could be explained in terms of stabilized particles containing adsorbed polymers segments in the water solution. On the other hand, the shear-thickening behaviour, that is shown past the saturation adsorption concentration for Ergomix 1000, is due to weakly adsorbed or nonadsorbed polyacrilate segments of the additive, that increase steric hyndrance and that interparticle interactions [12].

In addition (see also Figure 9 which reports the variation of apparent viscosity with additive concentration at a fixed 


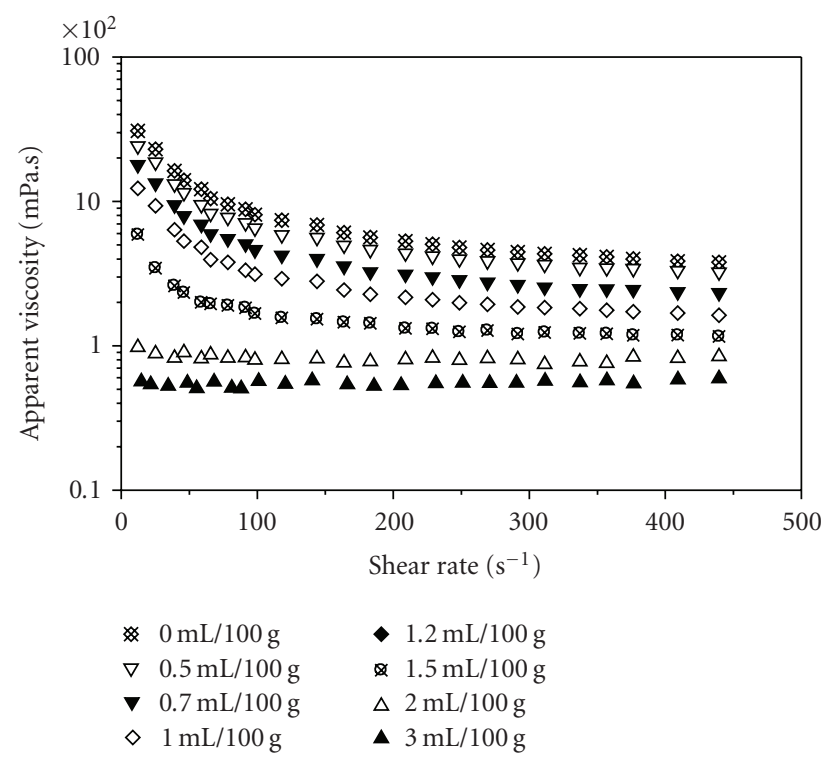

Figure 6: Apparent viscosity versus shear rate flow curves for the $\mathrm{W} / \mathrm{C}=0.42 \mathrm{HSPC}$ pastes investigated at various Concretan $200 \mathrm{~L}$ concentrations.

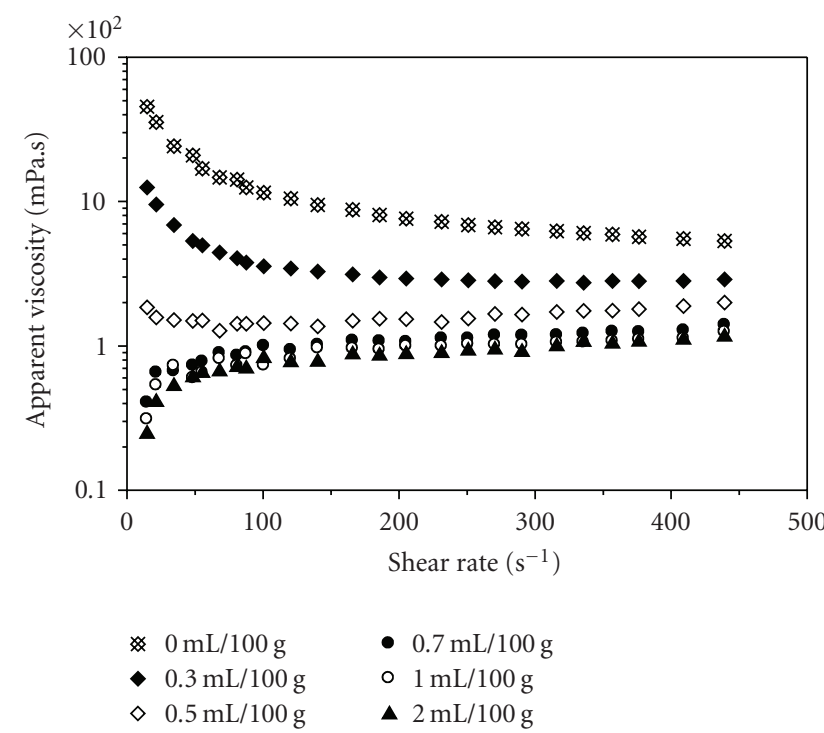

Figure 7: Apparent viscosity versus shear rate flow curves for the $\mathrm{W} / \mathrm{C}=0.38 \mathrm{HSPC}$ pastes investigated at various Ergomix 1000 concentrations.

shear rate), it can be seen that in the range of concentrations explored apparent viscosity always decreases when increasing superplasticizer concentration, so that no optimum dosage value can be clearly determinated for any additive.

Among superplasticizers employed, Ergomix 1000 shows the best effectiveness, thanks to its double mechanism of interaction which combines electrostatic repulsion with a remarkable hyndrance phenomenon.

By examining Figures 10, 11, and 12, which compare the variation of apparent viscosity with additive concentration for the HSPC and OPC pastes considered, it is also interesting

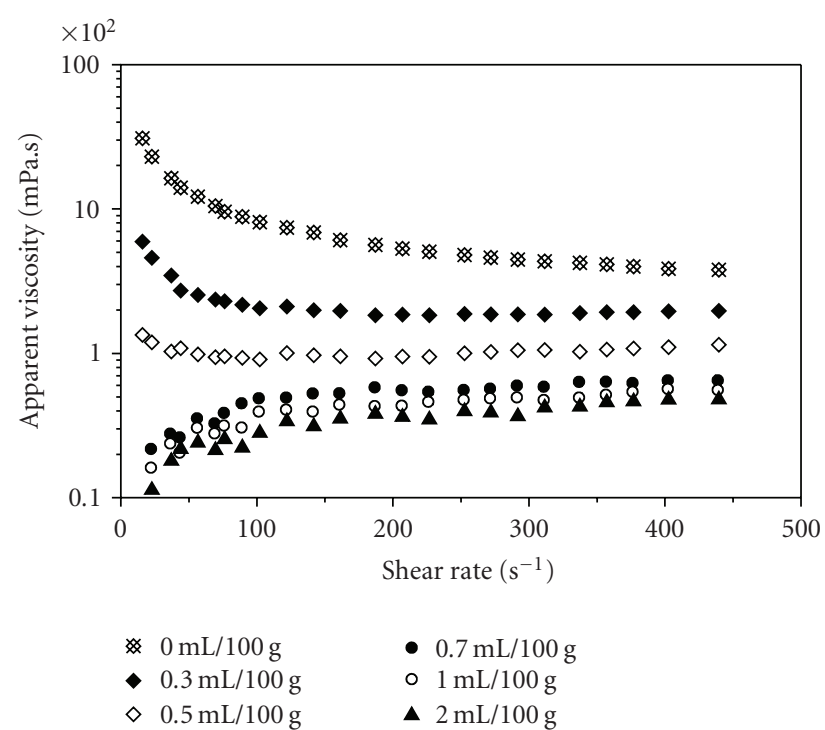

FIGURE 8: Apparent viscosity versus shear rate flow curves for the $\mathrm{W} / \mathrm{C}=0.42 \mathrm{HSPC}$ pastes investigated at various Ergomix 1000 concentrations.

to note that all the superplasticizers employed provoke upon the HSPC pastes a general much sharper decrease in viscosity than the OPC ones before and within the recommended dosage provided by the producer (except for very low dosages). Moreover, at the same superplasticizer concentration, viscosity values of $\mathrm{W} / \mathrm{C}=0.42 \mathrm{HSPC}$ paste are always lower than $\mathrm{W} / \mathrm{C}=0.32 \mathrm{OPC}$ paste within the whole dispersant concentration range tested, while $\mathrm{W} / \mathrm{C}=$ 0.38 HSPC paste shows similar or, more often, lower viscosity values than $\mathrm{W} / \mathrm{C}=0.32 \mathrm{OPC}$ paste within the recommended dosage provided by the producer (it must be reminded, as shown in Figure 2, that the $\mathrm{W} / \mathrm{C}=0.42 \mathrm{HSPC}$ paste shows the same viscosity of the $\mathrm{W} / \mathrm{C}=0.32 \mathrm{OPC}$ paste in the absence of additives).

Thus all of that indicates that the superplasticizers here investigated exert a major effectiveness upon the HSPC pastes rather than the OPC ones.

This is due (as reported previously) to the higher specific surface (milling finess) of the particles of a powder of HSPC rather than OPC disposable for adsorption of admixture molecules on the solid surface, thus promoting a better dispersing action of cement particles. On the other side higher specific surface enhances the attractive forces among cement particles (taking also into account adsorbed water molecules onto particles surface), thus explaining the higher viscosity of HSPC plains suspensions than OPC pastes formulated with the same water/cement ratio.

\section{Conclusions}

(1) Plain HSPC pastes prepared at different W/C ratio show shear-thinning behaviour and, as could be expected, higher viscosity than OPC pastes formulated with the same water/cement ratio. 


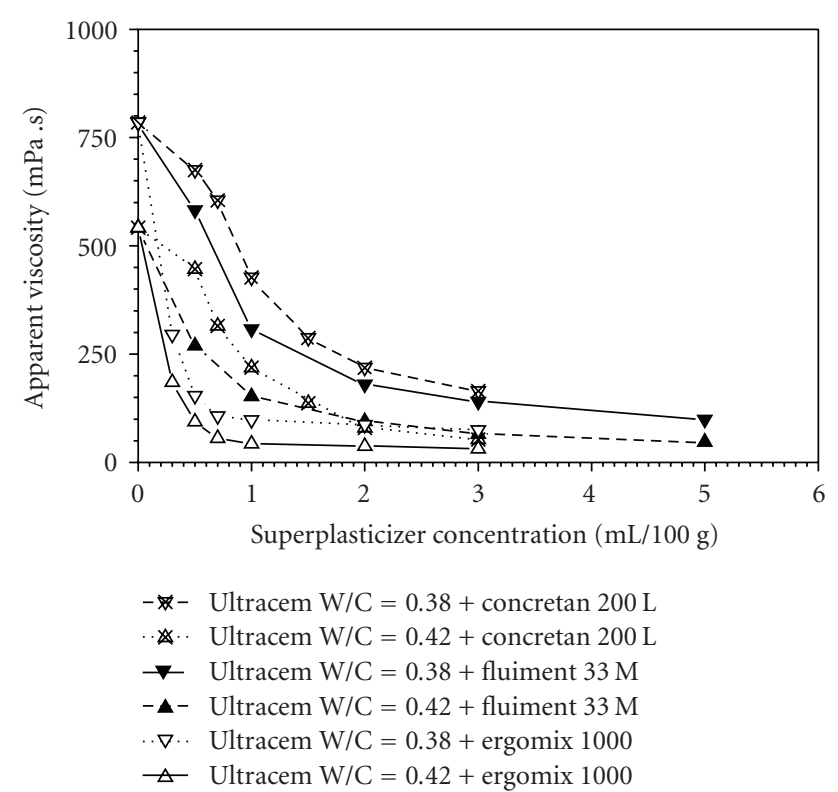

FIGURE 9: Apparent viscosity versus superplasticizer concentration for the $\mathrm{W} / \mathrm{C}=0.38$ and $\mathrm{W} / \mathrm{C}=0.42 \mathrm{HSPC}$ pastes investigated (shear rate $\left.=200 \mathrm{~s}^{-1}\right)$.

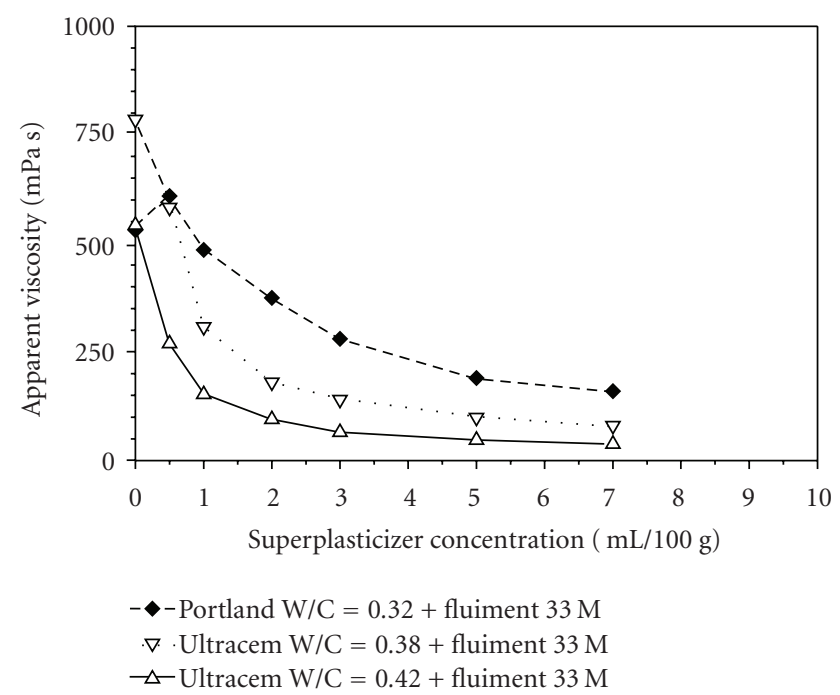

Figure 10: Apparent viscosity versus Fluiment $33 \mathrm{M}$ concentration for the $\mathrm{W} / \mathrm{C}=0.38$ and $\mathrm{W} / \mathrm{C}=0.42 \mathrm{HSPC}$ pastes investigated and the $\mathrm{W} / \mathrm{C}=0.32$ OPC paste $\left(\right.$ shear rate $=200 \mathrm{~s}^{-1}$ ).

(2) The pastes containing the superplasticizers that have been studied in this work clearly exhibit shear-thinning behaviour at low additive concentration; with increasing superplasticizer dosage, a critical deflocculant concentration is reached above which almost Newtonian properties for the pastes added with Fluiment $33 \mathrm{M}$ and Concretan 200 $\mathrm{L}$ and shear-thickening behaviour for the pastes added with Ergomix 1000 are found.

(3) Apparent viscosity always decreases when increasing superplasticizer concentration, so that not any value of optimum dosage but also a superplasticizer concentration

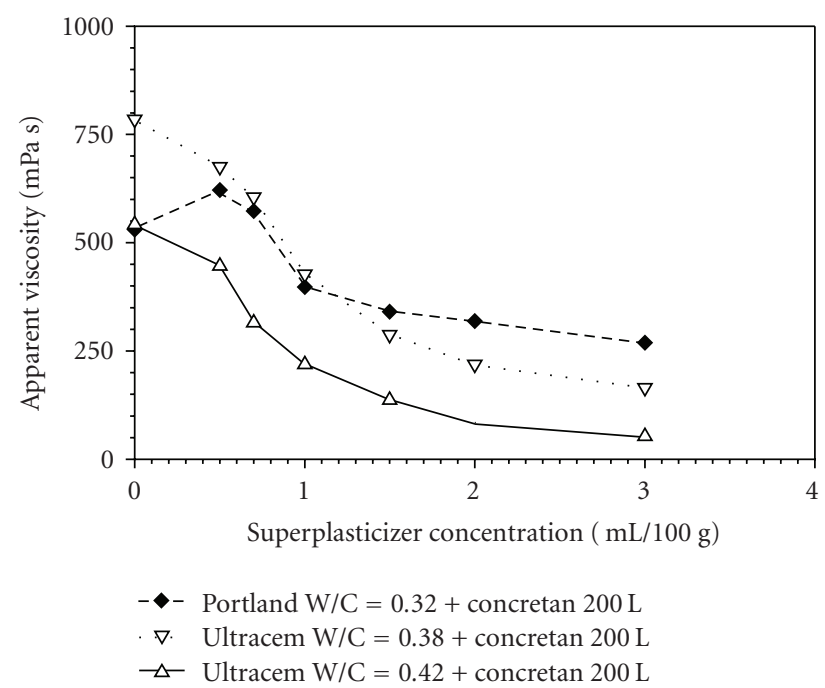

FIGURE 11: Apparent viscosity versus Concretan $200 \mathrm{~L}$ concentration for the $\mathrm{W} / \mathrm{C}=0.38$ and $\mathrm{W} / \mathrm{C}=0.42 \mathrm{HSPC}$ pastes investigated and the $\mathrm{W} / \mathrm{C}=0.32$ OPC paste $\left(\right.$ shear rate $\left.=200 \mathrm{~s}^{-1}\right)$.

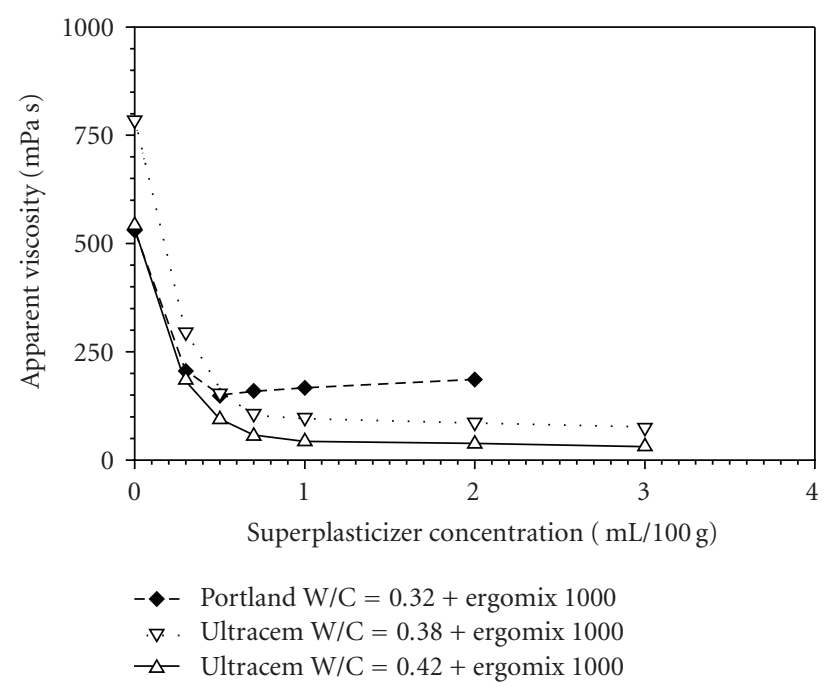

FIgURE 12: Apparent viscosity versus Ergomix 1000 concentration for the $\mathrm{W} / \mathrm{C}=0.38$ and $\mathrm{W} / \mathrm{C}=0.42 \mathrm{HSPC}$ pastes investigated and the $\mathrm{W} / \mathrm{C}=0.32$ OPC paste $\left(\right.$ shear rate $\left.=200 \mathrm{~s}^{-1}\right)$.

range within which paste viscosity presents very low values can be clearly determined for any additive.

(4) The effectiveness of the superplasticizers tested in this work is higher for the HSPC pastes than for the OPC ones at the concentrations here studied.

(5) Among the three superplaticizers here employed, Ergomix 1000 shows the highest effectiveness for the HSPC pastes investigated at the dispersant concentrations tested in this work.

A better knowledge of the properties of these materials can allow to optimize the ratio between production costs and quality characteristics required by different fields of utilization. 


\section{References}

[1] L. D. Schwartzentruber, R. Le Roy, and J. Cordin, "Rheological behaviour of fresh cement pastes formulated from a Self Compacting Concrete (SCC)," Cement and Concrete Research, vol. 36, no. 7, pp. 1203-1213, 2006.

[2] E. A. M. Gad, M. R. Mabrouk, and F. H. Mosallamy, "Rheological properties of different cement pastes made with different admixtures," Silicates Industriels, vol. 70, no. 3-4, pp. 59-64, 2005.

[3] A. Papo, L. Piani, and R. Ricceri, "Optimization of Portland cement pastes," Silicates Industriels, vol. 70, no. 9-10, pp. 149 152, 2005.

[4] M. Lachemi, K. M. A. Hossain, V. Lambros, P.-C. Nkinamubanzi, and N. Bouzoubaâ, "Performance of new viscosity modifying admixtures in enhancing the rheological properties of cement paste," Cement and Concrete Research, vol. 34, no. 2, pp. 185-193, 2004.

[5] A. Papo and L. Piani, "Effect of various superplasticizers on the rheological properties of Portland cement pastes," Cement and Concrete Research, vol. 34, no. 11, pp. 2097-2101, 2004.

[6] A. Papo and L. Piani, "Flow behavior of fresh Portland cement pastes," Particulate Science and Technology, vol. 22, no. 2, pp. 201-212, 2004.

[7] I. Aiad, A. A. Mohammed, and S. A. Abo-El-Enein, "Rheological properties of cement pastes admixed with some alkanolamines," Cement and Concrete Research, vol. 33, no. 1, pp. 9-13, 2003.

[8] I. Aiad and M. Heikal, "Effect of some superplasticizers on the rheological properties of blended cement pastes containing condensed silica fume," Silicates Industriels, vol. 67, no. 11-12, pp. 129-134, 2002.

[9] G. Schmidt and E. Schlegel, "Rheological characterization of C-S-H phases-water suspensions," Cement and Concrete Research, vol. 32, no. 4, pp. 593-599, 2002.

[10] L. Nachbaur, J. C. Mutin, A. Nonat, and L. Choplin, "Dynamic mode rheology of cement and tricalcium silicate pastes from mixing to setting," Cement and Concrete Research, vol. 31, no. 2, pp. 183-192, 2001.

[11] C. F. Ferraris, K. H. Obla, and R. Hill, "The influence of mineral admixtures on the rheology of cement paste and concrete," Cement and Concrete Research, vol. 31, no. 2, pp. 245-255, 2001.

[12] M. Cyr, C. Legrand, and M. Mouret, "Study of the shear thickening effect of superplasticizers on the rheological behaviour of cement pastes containing or not mineral additives," Cement and Concrete Research, vol. 30, no. 9, pp. 1477-1483, 2000.

[13] H. Hodne, A. Saasen, A. B. O'Hagan, and S. O. Wick, "Effects of time and shear energy on the rheological behaviour of oilwell cement slurries," Cement and Concrete Research, vol. 30, no. 11, pp. 1759-1766, 2000.

[14] L. Opoczky and A. Papo, "Rheological and hydration properties of a high strength gypsum-free cement," in Proceedings of the 10 International Congress on the Chemistry of Cement (ICCC '97), H. Justnes, Ed., vol. 2, Göteborg, Sweden, June 1997, Cement Hydration, 2004.

[15] S. A. Abo-El-Enein, S. Hanafi, F. I. El-Hosiny, E.-S. H. M. El-Mosallamy, and M. S. Amin, "Effect of some acrylatepoly (ethylene glycol) copolymers as superplasticizers on the mechanical and surface properties of Portland cement pastes," Adsorption Science \& Technology, vol. 23, no. 3, pp. 245-254, 2005.

[16] S. Chandra and J. Björnström, "Influence of superplasticizer type and dosage on the slump loss of Portland cement mortars-part II," Cement and Concrete Research, vol. 32, no. 10, pp. 1613-1619, 2002.

[17] J. Roncero, S. Valls, and R. Gettu, "Study of the influence of superplasticizers on the hydration of cement paste using nuclear magnetic resonance and X-ray diffraction techniques," Cement and Concrete Research, vol. 32, no. 1, pp. 103-108, 2002.

[18] R. J. Flatt and Y. F. Houst, "A simplified view on chemical effects perturbing the action of superplasticizers," Cement and Concrete Research, vol. 31, no. 8, pp. 1169-1176, 2001.

[19] S. Erdogdu, "Compatibility of superplasticizers with cements different in composition," Cement and Concrete Research, vol. 30, no. 5, pp. 767-773, 2000.

[20] M. Y. A. Mollah, W. J. Adams, R. Schennach, and D. L. Cocke, "Review of cement-superplasticizer interactions and their models," Advances in Cement Research, vol. 12, no. 4, pp. 153-161, 2000.

[21] R. J. Flatt, Y. F. Houst, R. Oesch, et al., "Analysis of superplasticizers used in concrete," Analusis, vol. 26, no. 2, pp. M28-M35, 1998.

[22] A. Papo, L. Plani, L. Ceccon, and V. Novelli, "Effect of various superplasticizers on the rheological properties of very high strength Portland cement pastes," Silicates Industriels, vol. 73, no. 11-12, pp. 227-232, 2008.

[23] D. H. Napper, Polymeric Stabilization of Colloid Dispersions, Academic Press, London, UK, 1983.

[24] J. Cesarano III and I. A. Aksay, "Processing of highly concentrated aqueous $\alpha$-alumina suspensions stabilized with polyelectrolytes," Journal of the American Ceramic Society, vol. 71, no. 12, pp. 1062-1067, 1988.

[25] Technical schedule Ultracem $52.5 \mathrm{R}$ by Italcementi S.p.A.

[26] Technical schedule Fluiment 33 M, Concretan 200 L, Ergomix 1000 by Ruredil S.p.A.

[27] D. M. Kalyon and H. Gevgilili, "Wall slip and extrudate distortion of three polymer melts," Journal of Rheology, vol. 47, no. 3, pp. 683-699, 2003.

[28] B. K. Aral and D. M. Kalyon, "Effects of temperature and surface roughness on time-dependent development of wall slip in steady torsional flow of concentrated suspensions," Journal of Rheology, vol. 38, no. 4, pp. 957-972, 1994.

[29] H. Gevgilili and D. M. Kalyon, "Catastrophic failure of the no-slip condition at the wall during torsional flows and development of gross surface irregularities during capillary flow of three polymers," Society of Plastics Engineers ANTEC Technical Papers, vol. 1, pp. 1019-1023, 2002.

[30] D. S. Kalika and M. M. Denn, "Wall slip and extrudate distortion in linear flow density polyethylene," Journal of Rheology, vol. 31, no. 8, pp. 815-837, 1987.

[31] S. G. Hatzikiriakos and J. M. Dealy, "Wall slip of molten high density polyethylene. I. Sliding plate rheometer studies," Journal of Rheology, vol. 35, no. 4, pp. 497-523, 1991. 

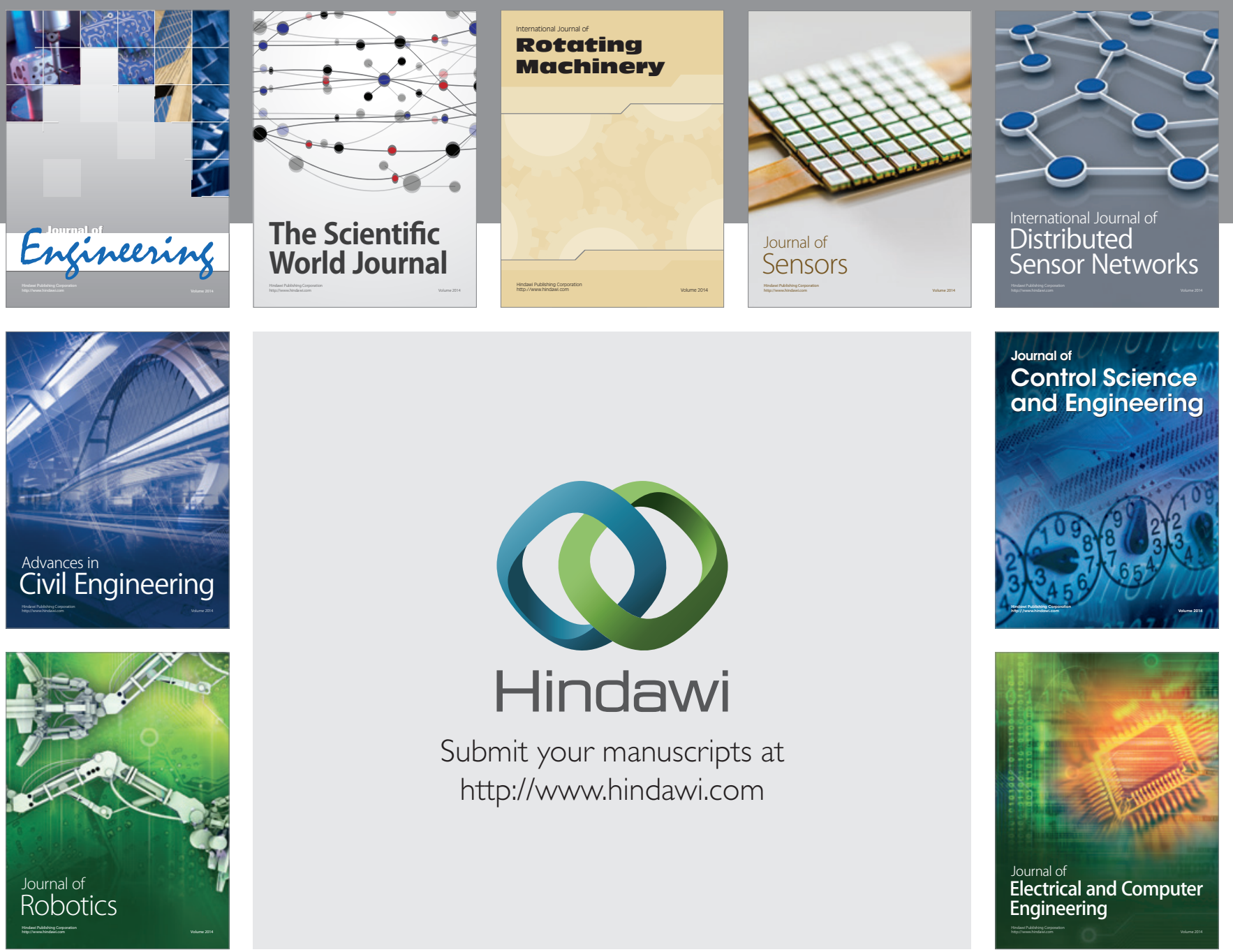

Submit your manuscripts at

http://www.hindawi.com
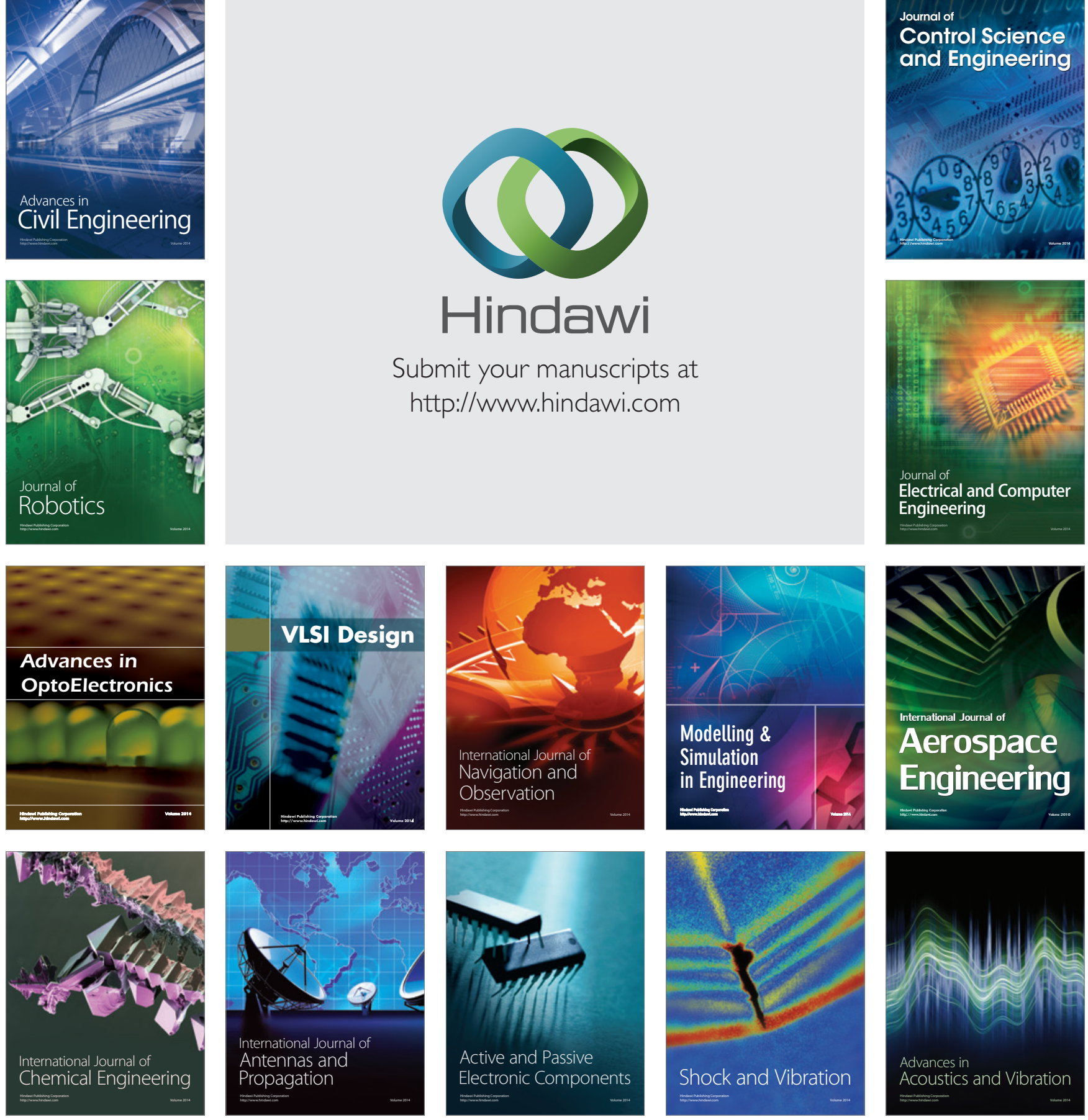